\title{
Violencia doméstica en la tercera edad
}

\author{
Domestic violence at the older age
}

\author{
Florángel Urrusuno Carvajal ${ }^{\mathrm{I}}$; Roberto Rodríguez Fernández ${ }^{\mathrm{II}}$; Regla Lidia \\ Vázquez Abreu ${ }^{\text {III }}$
}

\author{
IEspecialista de II Grado en Medicina General Integral. Máster en Atención Primaria \\ de Salud. Universidad de Ciencias Médicas "Cdte. Manuel Fajardo". La Habana, \\ Cuba.

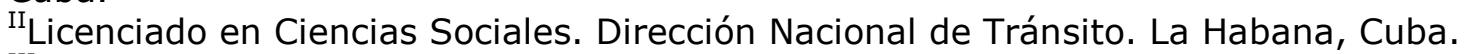 \\ IIIEspecialista de I Grado en Medicina General Integral. Dirección Municipal de Salud \\ del Cerro. La Habana, Cuba.
}

\section{RESUMEN}

La violencia doméstica es tan antigua como la humanidad. Se reconoce la violencia infantil, contra la mujer y al anciano El último grupo está conformado por una población en ascenso por las mayores expectativas de vida de los últimos años dadas, entre otros factores, por los avances médicos actuales y los estilos de vida saludables. Cuba tiene actualmente el $13 \%$ de la población con 65 años y más y según estimados, para el 2020 existirán por primera vez más ancianos que niños. Por ello, en los próximos años habrá que seguir de cerca el trato a este grupo poblacional. Es de esperar que se incremente el abuso contra el anciano y el impacto de este abuso sobre la salud debe ser considerado. La gama de maltratos que puede sufrir el anciano incluye fundamentalmente, el abuso físico, emocional, financiero, sexual, por negligencia y la negación a brindarle ayuda. Garantizarles condiciones de vida que les ofrezcan independencia, protegerlos jurídicamente, crearles espacios adonde acudir para reclamar por las violaciones que pudieran sufrir y brindarles información a ellos y a la sociedad sobre las formas en que se puede manifestar el maltrato, son acciones que deben cumplirse con exactitud y que contribuirían a la prevención de la violencia.

Palabras clave: Violencia doméstica, ancianos, tercera edad. 


\section{ABSTRACT}

Domestic violence is as old as the origin of mankind. Infant violence and violence against the woman and the old person are well known. The older people group represents a growing population due to higher life expectancies in the last few years encouraged by the present medical advances and healthier life styles. Nowadays, $13 \%$ of the Cuban population is 65 years and over; but according to estimates, the elderly will outnumber the children for the first time in 2020. Therefore, one must closely watch the treatment to this population section in the forthcoming year. It is expected that elder abuse grows, so the impact of abuse on health should be taken into account. Mistreatment of the elderly mainly includes physical, emotional, financial, sexual abuse, negligence and denial of assistance. Providing them with living conditions that encourage independence, protect them from the legal viewpoint, creating adequate sites where they may claim for possible violations and giving them and the society information on the various forms of abuse are all actions that should be fully taken since they will contribute to the prevention of violence.

Key words: Domestic violation, elderly, older age.

La vejez siempre ha estado entre nosotros y, a lo largo de la Historia, se revelan múltiples evidencias de la certeza de esta aseveración. Los antiguos egipcios y el autor de los doce capítulos del Eclesiastés estaban familiarizados con las discapacidades atribuibles a los ancianos.

El problema es global, creciente e influido altamente por la desigualdad formal y real entre el hombre y la mujer y reflejo del dominio machista, por lo menos así lo afirman estudiosos del tema. ${ }^{1}$

La violencia contra el adulto mayor es un fenómeno mundial que también toca a las puertas de los hogares cubanos. Por lo general, se habla del maltrato infantil y femenino, pero el que se manifiesta de manera aislada o reiterada con los ancianos en centros de trabajo, vecindarios, instalaciones de salud y en la propia familia, aún permanece invisible ante los ojos de las sociedades actuales. ${ }^{1}$

La vejez es una etapa de la vida donde se tiende a la creciente dependencia de los otros. Las maneras de atacar a los ancianos van desde las muy sutiles, como una frase incisiva y humillante, hasta el abuso físico, emocional, psicológico, financiero, sexual, la desatención, negación a brindarle ayuda, abandono, intimidación, injurias orales, golpes y episodios criminales; aspectos que son causantes de nerviosismo, temores, depresión, baja autoestima, aislamiento, inactividad, entre otras. Los ancianos con deterioro cognitivo son los más vulnerables. ${ }^{1-3}$

Mientras más longevo, el anciano con limitaciones físicas o enfermedades crónicas suele ser blanco fácil de las agresiones. Por encima de los hombres, las mujeres son frecuentemente las víctimas, en especial aquellas abuelas complacientes y pasivas que, en algunos casos, todavía se mantienen esclavizadas con las tareas domésticas. ${ }^{1}$ 
Lo que se ha dado en llamar violencia doméstica, en su aspecto más abarcador incluye el abuso contra cualquier miembro familiar, sin embargo el uso más extendido se centraliza en el maltrato en general. No obstante, la psicología actual, tras diversas investigaciones, proporciona un nuevo enfoque e introduce también el maltrato que destruye la autoestima de una persona mediante burlas, insultos, abandonos o humillaciones. Por añadidura, habitualmente la agresión verbal o psicológica precede a la física.

La violencia doméstica es tan antigua como la humanidad misma y se reconoce la violencia infantil, contra la mujer y al anciano, fundamentalmente. Este último grupo es una población en ascenso por las mayores expectativas de vida de los últimos años y los estilos de vida saludables. Como resultado de ello, el número de casos de abuso en el anciano se incrementará y el impacto de este abuso sobre la salud debe ser considerado de forma apropiada. ${ }^{2}$ El médico en la atención primaria de salud es un pilar importante en la prevención y educación de este problema.

En 1990 se estimó que la población envejecida en los EE.UU. era del $13 \%$, y para el año 2025 está proyectado un incremento de $25 \%$, y la población que sobrepase los 85 años será el doble de la actual. Cuba no está exenta de esas estadísticas, y con el desarrollo de la salud pública se sabe que aproximadamente el $13 \%$ de la población tiene 65 años y más, y este fenómeno va en ascenso.

Las definiciones y terminologías usadas para relacionar el abuso en el anciano varían según las leyes de cada estado. Hay que distinguir entre el maltrato premeditado, y por tanto, punible y el maltrato por ignorancia, no pretendido, pero con efectos perjudiciales para la víctima.

Desde hace varios años se percibe un fenómeno que influye de manera negativa en la sociedad. Los hijos pierden cada vez más el sentido de la responsabilidad y cargan de trabajos a los adultos mayores que conviven con ellos, privándolos de realizar actividades para su disfrute.

Antiguamente los criterios y opiniones de las personas de la tercera edad se tomaban más en cuenta. Los hijos, al casarse, asumían una vida independiente, se valían por sí solos y trataban por todos los medios de no recargar a sus padres de tareas, al tiempo que respetaban su espacio.

Hoy no ocurre lo mismo. La vida se vuelve cada vez más agitada y el peso del hogar, en gran medida, descansa sobre las espaldas de los adultos mayores, en algunos casos porque así lo prefieren y en otros porque el resto de la familia se lo impone.

Por ley de la naturaleza, el adulto mayor pierde facultades físicas y mentales, atenderlo con dignidad precisa amor y paciencia. Desde luego, no pocas veces el cuidador está expuesto al trabajo agotador sin descanso, a la falta de tiempo y espacio personal, al aislamiento psicosocial y a otras presiones que lo pueden llevar a actuar de manera impensada. Conocer esos riesgos ayuda a ponerse en su lugar.

Una vez que las personas se jubilan pasan a desempeñar un papel importante en las tareas domesticas: buscar el periódico, acompañar al nieto a la escuela, llevar la merienda, hacer el almuerzo, buscar los mandados a la bodega, entre otras actividades que componen su rutina diaria.

Según estimados, para el 2020 en Cuba existirán por primera vez más ancianos que niños. Por ello, en los próximos años habrá que seguir de cerca el trato a este 
grupo poblacional. ¿Cómo enfrentaremos el problema, tan antiguo como las civilizaciones de los mismos teutones y griegos? ${ }^{4}$

Garantizarles condiciones de vida que les ofrezcan independencia, protegerlos jurídicamente y crearles espacios adonde acudir para reclamar por las violaciones de su integridad, hacerlos conscientes a ellos y al resto de las personas de qué es la violencia, son acciones que deben cumplirse con exactitud.

En Cuba, donde la población mayor de 65 años representa el 10,6\% del total de habitantes, los ancianos tienen asegurada su vejez, y también poseen el derecho a la superación mediante la Universidad del Adulto Mayor, proyecto encaminado, entre otros asuntos, a orientar a las personas mayores en cuanto al papel que deben asumir en el seno de la familia, además, los círculos de abuelos, los hogares de ancianos y otros proyectos que los vinculan con las tareas de la Revolución y les permiten sentirse útiles todavía.

Generalmente, quienes tienen bastante juventud acumulada enfrentan determinados cambios físicos y psicológicos. Su autoestima decae en un alto porcentaje, temen a las enfermedades por simples que sean, pues ven próxima la muerte, se sienten cada vez más decaídos y con menos fuerza, empiezan a rendir menos en el trabajo y a considerarse una molestia para sus hijos y nietos, quienes en muchísimas ocasiones tampoco ayudan a eliminar estos sentimientos negativos, por el contrario, viven quejándose de las cosas que hacen sin entender que son propias de esa edad.

Los abuelos son seres comprensivos, dotados de un caudal de experiencia adquirida con los años, llenos de amor para dar y de ganas de trabajar, aunque muchos tienen limitaciones que no les permiten hacer las cosas que hacían 20 años atrás.

Envejecer es un proceso natural, donde se producen transformaciones biológicas y psíquicas, con amplia repercusión en la esfera de las relaciones del individuo, hasta el momento es irreversible y se comporta de manera distinta en cada ser humano. No obstante, una porción significativa de la humanidad necesita tener conciencia clara de que los seres humanos envejecen y ello no significa que con la acumulación de los años sean esclavos y pierdan todos los derechos y ni mucho menos que sean considerados ciudadanos de segunda categoría. Si bien es cierto que los ancianos siempre tienen una solución para todo, un consejo, no es menos cierto que necesitan de comprensión, ayuda y cuidados por parte de quienes los rodean (Fernández A. ¿La última carta de la baraja? Revista Somos Jóvenes).

Con solo un poco de amor se puede contribuir a que los ancianos sean felices. Es necesario ayudar a eliminar los prejuicios sociales que ensombrecen su felicidad, dedicar todo el tiempo que sea posible a conversar con ellos, a nutrirse de sus experiencias y dejarles su espacio, tolerar las cosas propias de esa etapa y darles el cuidado y el apoyo que necesitan para que no se sientan solos.

Ningún esfuerzo de la Revolución será útil ciento por ciento si primero no hay un cambio en la manera propia de actuar.

La prevención de la violencia en el adulto mayor es una prioridad en la voluntad política del gobierno cubano, basada en métodos que conducen al mejoramiento de la calidad de vida en todos los sentidos, sirviéndose cada día de sus herramientas y habilidades que enriquecen la tarea diaria de formar nuevas generaciones con principios y valores acorde al sistema socialista. 


\section{REFERENCIAS BIBLIOGRÁFICAS}

1. Dolan VF. Risk factors for elder abuse. J Insur Med. 1999;31(1):13-20.

2. Swagerty DL Jr, Takahashi PY, Evans JM. Elder mistreatment. Am Fam Physician. 1999;59(10):2804-8.

3. Attie T. Violencia social silenciosa. Psicol Iberoam. 1995;3(3):53.

4. Belmonte N. Variaciones sobre la violencia. Psicol Iberoam1995;3(3):9-10.

Recibido: 25 de octubre de 2008.

Aprobado: 30 de octubre de 2008.

Florángel Urrusuno Carvajal. Universidad de Ciencias Médicas "Cdte. Manuel Fajardo". Zapata y C. Plaza 10400. La Habana, Cuba.

E-mail: florangel.urrusuno@infomed.sld.cu 